\title{
Study on the Influence Mechanism of Urban Residents' Energy-Saving Awareness on Energy-Saving Behaviors
}

\author{
Jun Chen ${ }^{1, a}$, Zhongfu Qin ${ }^{1, b^{*}}$ \\ 'Zhejiang University,Hangzhou ,Zhejiang P.R.China, \\ a 3061079613@qq.com, ${ }^{\text {b }}$ qinzhongfu@zju.edu.cn
}

\begin{abstract}
Keywords: Energy-saving awareness; Energy-saving behavior; Theory of planned behavior; Theoretical model
\end{abstract}

\begin{abstract}
Energy conservation is currently one of the popular issues in academic research, while the specific impacts of consciousness in energy conservation are still the focus of research. In order to clarify how awareness in energy-saving plays a role in energy-saving behavior, this study will take urban residents as research object and integrates relevant literature and disciplines such as psychology and sociology, to the study of the mechanism of how energy-saving awareness affects energy-saving behavior, and establish a reasonable research model. Finally, the comprehensive research model is developed and applied on the basis of the theory of planned behavior, and put forward influencing factors of energy-saving behavior such as energy-saving knowledge, subjective norms, perceived self-efficacy, personal norms, perceived behavior control, external factors and demographic characteristics, etc., resulting in the formation of energy-saving behavior in the research process.
\end{abstract}

\section{Introduction}

Energy issue has now become the focus of national politics, energy shortage is as well a worldwide challenge. Since the 90s, China's continual economic development has led to a rapid growth in energy consumption. In 1993, China was transformed from a net exporter to an energy net importer. The total energy consumption has been exceeding the total supply, and hence external dependences for energy demand increases rapidly. As the absolute population size in China is relatively vast, along with social and economic developments, residents' demand for life qualities improvement has been continuously increased. This caused residential energy consumption being an important growth factor as a result. Therefore, the guidance of energy-saving behavior is particularly important.

In the process of researching individual behaviors, scholars have put forward many theories explaining personal behavior. The theory of planned behavior provides a valuable theoretical perspective for understanding individual energy-saving behavior, and is one of the relatively we31l developed and effective research theories in behavior. Ajzen (1991) adds the Perceived Behavior Control variable on the basis of the Theory of reasoned behavior, which enhances the explanatory power of the model [1]. Justin Paul et al (2016) adds the environmental concern variables to the research of the prediction of green product consumption and extends the TPB mode in order to predict consumer behaviors [2]. Chen and Tung (2014) constructs a theory model of extended plan behavior that includes environmental awareness and perceptual moral obligation through the use of TPB model [3]. Through the survey targeted to Australians, Price et al (2014) find that residents' environmental values have a significant impact on their behaviors [4]. Klöckner (2013) proposes a comprehensive model by using a meta-analytical structural equation modelling approach based on a pool of 56 different data sets with a variety of target behaviors [5].

Previous researches in energy-saving awareness and energy-saving behaviors are mostly associated with a designed scale and surveys, analyzing the relationships between the two factors. Yet the metabolism is usually left on the surface in absence of deep investigations. On the basis of the theory of planned behavior, this paper explores the relationship between energy-saving awareness and energy-saving behavior in residential lives, and establishes an optimized 
comprehensive model to provide new ideas for studying the formation mechanism of energy-saving behavior.

\section{Concept Definition}

Definition of Energy-saving Awareness. The definition of awareness is a basic question but also the controversial issue in the psychology field that has not reached a consensus. Some scholars suggest the concepts of behaviors cannot be defined considering the research in behaviors are still incomplete, likewise the meanings and functions of behaviors are still unknown. Others realize providing an accurate definition is not necessary, and can solely offer research aspects and boundaries for such issue.

Consciousness can be seen in generalized concept and narrow sense in psychology. The generalized consciousness is the integration of mental factors such as sensation, perception, emotion, motivation and attention. The narrow sense of consciousness refers to human cognition and consciousness [6].

So far, the understanding of human brain activities is still very limited, the activities of psychology, cogitation, and awareness can not be directly explained from the perspective of biological organs. So the approach of studying mental activity is still based on Black Box, that is, through the process of information exchange between human brain and the outside world [7]. Many scholars believe that awareness and psychology to some extent is the same, thus awareness should be the unity of cognition, emotion and will.

This paper suggests that giving a comprehensive definition for awareness is a challenging task. Hence it is acceptable, for the time being, to study and analyze behaviors within a certain environment, and offer a definition in this specific condition. Such research uses the understanding in awareness from psychological viewpoints to explore the impact of awareness on behavior in the level of psychology and defines energy-saving awareness as "individuals' understanding of energy issues, energy-saving emotional judgments, choice intention of energy-saving behavior and generation, maintenance and termination of other forms of psychological activities". From the above definition, it can be seen that energy-saving awareness is not only a few awareness factors or the sum of ideological forms. It is rather a type of continuous state, through monitoring each psychological activity process and result, consequently the self-consciousness to constantly modulate explicit behaviors.

Energy-saving awareness is built upon the basis of self-awareness, reflecting the relationship between individuals and the surrounding environment, which the main forms of expression are cognition, emotion and will. Awareness is individuals' knowledge and comprehension for objective things, including senses, attention and imagery; Emotions are the attitude experience for objects when it matches the needs, it is the process for moral judge; Whilst will is the action of self consciously setting aims, as well as a psychological process when individuals act out and overcome the aimed tasks.

Definition of Energy-Saving Behavior. Stern (2000) believes that we can define environmental behavior from two dimensions of "impact" and "intention". Impact-oriented definition addresses the impact of behavior on the environment. Intent-oriented definition emphasizes the purpose of individual behavior. He also points out that the impact-oriented definition can better analyze the behavior of the target, and understand the real impact of target behavior on the environment. If the researcher wishes to understand and alter some of the environmental behaviors that people regularly do, have done, or want to do, he should adopt a guided definition in order to focus the study on psychological factors such as beliefs and motivations [8]. The purpose of this study is to explore the influencing factors of energy-saving behavior, to understand peoples' awareness, motivation and other psychological factors, and then understand and change peoples' behavior, and promote adopting energy-saving behavior. So, we should apply intention-oriented definition when we define energy-saving behaviors.

To define energy-saving behavior, we must realize that, compared to residents' subconscious non-energy-saving behavior, energy-saving behavior is a self-controlling behavior that needs 
conscious control and regulation. Kanfer (1991) suggests that the self controlling behaviors are resulted when new behavior modes are being learnt or habitual reactions being interrupted. He adds that under any conditions, before individuals' trials in controlling their behaviors, individuals must firstly aware of the actions, judge them, and make decisions in the known and legit modes of behaviors, so as to reach an optimized self-controlling effect [9]. Therefore, this study believes that energy-saving behavior is a self-controlling behavior of reducing energy consumption that individuals in the external stimulus consciously taken in daily life.

\section{Relationship between Energy-saving Behaviors and Habits/Customs/Practices}

The creation of habits is the result of repetitive behaviors, continuous repetitive actions under stable conditions realize automatism of such behaviors. Developed habitual practices are not sustained by cognition, and simply needs awareness in the starting and ending stage, which reflects the automation and unconsciousness in habits.

According to the nature in habits, it can be seen that the creation of habits is mainly affected by behavioral frequencies and stable influence in environments. It is likewise that habits are carried out under unconsciousness, hence our research believes habits is a type of behavior mode, and not the needs and propensity in a conscious level.

Created habits are relatively stable, and advances the mutual relations for behaviors. Behaviors that are repeated further promotes consolidation of habit creation, where habits push the next creation of behaviors. In the process of building new habits, individuals initially receive stimulus from external message, then reacts by the eager to stick with original customs but at the same time urges to make self changes. In this case the external stimulus and the decision to make changes are contributed to the process of emotional judge, and finally decide whether he or she will alter own behaviors. Once he has chosen to make changes, the awareness would interrupt the original habits, the cuts the unconscious connections between habits and behaviors. This ultimately adds awareness influence on new behaviors, and advocates the creation of new behaviors.

According to the above process, the original behaviors can hinder the formation of energy-saving behaviors, however when energy-saving behaviors are performed multiple times, new habits will eventually be built. That is, energy-saving behaviors replacing the original habits, thus habits in energy-saving behaviors can advocate creations of energy-saving behaviors. The process in relations between habits and behaviors are depicted as below.

\section{The Process of Energy-Saving Awareness Affecting Energy-Saving Behavior}

This research focuses on relationship between energy-saving awareness and energy-saving behavior, by researching inner awareness through explicit behavior, soon after finds out the methods to control behavior. Therefore, to understand how awareness affects behavior, we should explore the process of the awareness formation, because it affects behavior. Behavior is the ultimate external performance of all factors, and awareness is the most important inner influential factor. Through the study of the formation process of awareness, that is, the process of various constituent factors gradually entering into awareness, to explore the impact of energy-saving awareness on energy-saving behavior process. This research explores the process of energy-saving awareness affecting energy-saving behavior. Awareness is the unity of cognition, emotion and will, so the process of energy-saving awareness is divided into three stages: energy-saving cognition, energy-saving emotion and energy-saving will.

Energy-Saving Cognition. The emergence of awareness first of all needs stimulation from the external world. With the information input from the outer world, objective things produce a variety of understanding in the brain, bringing in sensory, perceived experience, and then produce internal activities such as emotion and will. Therefore cognition is a prerequisite for awareness. Through processing information, individuals produce emotions and attitudes towards the surroundings.

In addition to the objective information, outer stimulation also includes inputs that contain subjective and biased views. In abundant number of studies, many scholars believe that group and 
peers' attitude toward energy-saving behavior can pose pressure on individuals' energy-saving will. Fishbein and Ajzen (1977) put forward the concept of subjective norms, that is, when an individual is implementing an act, he or she will feel the pressure from society and others [10].

Energy-Saving Emotion. The existence of a subjective state is a distinctive feature of the way in which the structure of awareness exists. This feature determines that the structure of awareness is more directly affecting human practice and cognition than the generalized objectification [7]. By accepting the outside stimulation and integrating it with its past cognitive and experience, the brain makes the subjective emotional value judgments. This judgment can be hoggish, altruistic, or made from ecological perspective, depending on the individual's pattern of awareness. Through the trade-offs of information gains and losses, the emotional experience of saving energy will be formed.

Albert Bandura (1993) proposed the concept of perceived self-efficacy, perceived self-efficacy is the subjective expectation of the individual's ability to complete a specific behavior at a particular level [11]. Through outcome expectancy, individuals measure the energy efficiency and cost and produce the concept of implementing it or not. Through self-efficacy expectancy, individuals find out whether their own capacity is sufficient or not to conduct the behavior, and ultimately form the emotional experience of saving energy by integrating the two stages.

Energy-Saving Will. Having a preliminary desire to save energy does not mean that individuals will therefore take energy-saving behavior. Because the will produced by emotional experience is based on past experience and cognitive rational analysis, and not accorded with the context and specific conditions. So the occurrence of behavior is subject to external conditions. Will is the focus of the performance of awareness, and is a psychological process during which individuals overcome the difficulties and take action to achieve the desired goal. So the generation of action will be directly affected by the will, and external environmental conditions will also have a role in this process.

Ajzen (1991) defines "the degree to which an individual is to take control of energy efficiency and the required conditions" as Perceived Behavior Control [1]. Perceived behavior control has a positive effect on behavioral intention, and strong perceived behavior control can enhance the individual's willingness to execute behavior [12]. When the resistance of the implementation of energy-saving behavior posed by external conditions is relatively small, perceived behavior control will be strengthened, and then the positive behavior will be able to achieve active energy-saving behavior. On the contrary, when the resistance of the implementation of energy-saving behavior posed by external conditions is relatively large, perceived behavior control will be weakened.

\section{Influencing Factors of Energy-Saving Behavior}

Combined with the influencing factors put forward by each scholar and the relevant research on the energy-saving behavior, environmental behavior factors are summarized.

Table 1 Influencing factors of energy-saving behavior

\begin{tabular}{|c|c|c|c|}
\hline Category & Belief & Cognition & Emotion \\
\hline Factor & $\begin{array}{l}\text { Values } \\
\text { Personal consumption concept } \\
\text { Ecological values }\end{array}$ & $\begin{array}{l}\text { Energy problem sensitivity } \\
\text { Energy-saving knowledge } \\
\text { Saving consumption knowledge } \\
\text { Consciousness of consequences } \\
\text { Energy-saving skills }\end{array}$ & $\begin{array}{l}\text { Environmental assessment } \\
\text { Perceived self-efficacy } \\
\text { Environmental responsibility }\end{array}$ \\
\hline Category & Will & Norm & Situational factors \\
\hline Factor & $\begin{array}{l}\text { Perceived behavior control } \\
\text { Behavioral restriction }\end{array}$ & $\begin{array}{l}\text { Subjective norms } \\
\text { Social norms } \\
\text { Personal norms }\end{array}$ & $\begin{array}{l}\text { Policy } \\
\text { Economy } \\
\text { Culture } \\
\text { Publicity and education }\end{array}$ \\
\hline
\end{tabular}

By combing, the influencing factors of energy-saving behavior are summarized as six categories: 
beliefs, cognition, emotion, will, norm and situational factors.

Belief. The main content of the belief are the values. Values provide a measure of value for individuals to deal with the relationship between man and nature. It provides ideals and beliefs for life, value guidance for all social activities. It is a criterion for the evaluation of the whole world. The formation of values begins with the birth of the individual, under the influence of family and society. The impact of values on an individual is huge and relatively stable, so values are not subject to external interference and not easy to adjust. Therefore, this study excludes values from the research model.

Energy-Saving Cognition. Energy-saving cognition includes the cognition of energy issues, energy-saving consumption and environmental knowledge, energy-saving skills and other knowledge of energy-saving. For the generation of energy-saving behaviors, this cognition is basic for the reason that any self-control behavior first enters into the cognitive monitoring process. The content of energy-saving cognition is very rich, which can't be evaluated in all aspects, so energy-saving knowledge and energy issues are chosen as measurement indicators of energy-saving cognition.

Perceived Self-efficacy and Personal Norms. Environmental responsibility, environmental ethics and personal norms are the same concept, which is a sense of responsibility of the individuals in their own human society and self-development, and an experience of whether the completion of the moral task in their own moral activities meets moral needs. Therefore, it belongs to the scope of emotional experience.

Perceived self-efficacy is also an emotional judgment, the judgment of the result and implementation of their abilities and the behavioral subjects' inner perception.

Perceived Behavior Control. Perceived behavior control and perceived self-efficacy are all perceived by their own control execution ability, but the difference between perceived behavior control and perceived self-efficacy is that the former is more of external factors, that is, the extent of their own implementation of the difficulty under the influence of external factors. Mi (2011) and Yue (2014) have proposed to distinguish between perceived self-efficacy and perceived behavior control to identify the impact of individual will process on the behaviors more accurately $[13,14]$.

Subjective Norms. The subjective norms contain three elements: social norms, subjective norms and personal norms. In addition to the personal norms already mentioned above, the connotation of social norms is similar to that of the subjective norms. The subjective norm is the concept put forwarded by Ajzen in the theory of rational behavior, which mainly refers to the pressure of the important people and groups that the individual feels when choosing to take or not take an action. The social norm focuses on the code of conduct that the social groups abide by. The Subjective norms have an impact on individual behavior through cognitive processes and therefore they're an integral part of energy conservation.

Situational Factors. The situational factors are external factors, that is, external environment of the behaviors. Situational factors include policy factors, economic factors, cultural backgrounds and publicity and education.

Behavioral intention also exerts an impact on energy-saving behaviors. Most of the research about energy-saving behaviors, environmental behaviors will put behavioral intentions or behavioral purposes as the intermediary variables.

Besides, demographic characteristics and behavioral habits also work on energy-saving behavior.

Through the analysis of the influencing factors of energy-saving behaviors, it is found that energy-saving cognition and subjective norm belong to the cognitive category of awareness, while perceived self-efficacy and personal norms fall in the emotional category of awareness, and the behavior control awareness belongs to will category. So, it can be seen that the development of energy-saving behaviors is mainly affected by the energy-saving awareness, which is ultimately reflected in the intention of energy-saving behavior through the treatment and judgments of the external information, and energy-saving behavior and will affect the occurrence of energy-saving behaviors. 


\section{Comprehensive Model of Energy-Saving Awareness and Behaviors}

In the study of energy-saving behaviors model, different scholars choose different research methods. Some scholars rely on mature and perfect theories and models and add specific factors to meet the research objectives, as well as improve the structure of the original model; while the other scholars depend on empirical research and obtain data from the source by using rooting theory and other methods, so the results suggest factors. Because each scholar is not based on the same standard or thought of the impact of research factors, many factors proposed are repeated and similar to a certain extent, which bring the difficulty of understanding of the follow-up research work to. In this study, the influencing factors of most of the research are classified and classified, and the influencing factors of similarity are analyzed; therefore, the research model of energy-saving awareness and behaviors is established by studying the relationship between the entry order of various factors in the process of energy-saving behaviors and the impact relations among them.

In this model, the energy-saving awareness includes four parts: energy-saving cognition, energy-saving emotion, energy-saving will and energy-saving intention. Energy-saving awareness includes two aspects: energy-saving knowledge and subjective norm. Energy-saving emotion includes two factors: Perceived self-efficacy and personal norms. Energy-saving will only contain one factor, perceived behavior control, in which energy-saving behaviors will play a mediating role. Energy-saving intention can reflect a sense of attitude towards the behaviors. In addition, one's behavioral habits also have an impact on energy-saving behaviors. The original behavioral habits will hinder the occurrence of energy-saving behaviors, and energy-saving habits will promote the occurrence of energy-saving behaviors. The development of behavioral habits will also be affected by the energy-saving will in the process.

At the same time, this paper also takes the impact of external variables on energy-saving behaviors into consideration, such as policy factors, economic factors, cultural backgrounds and demographic characteristics. 


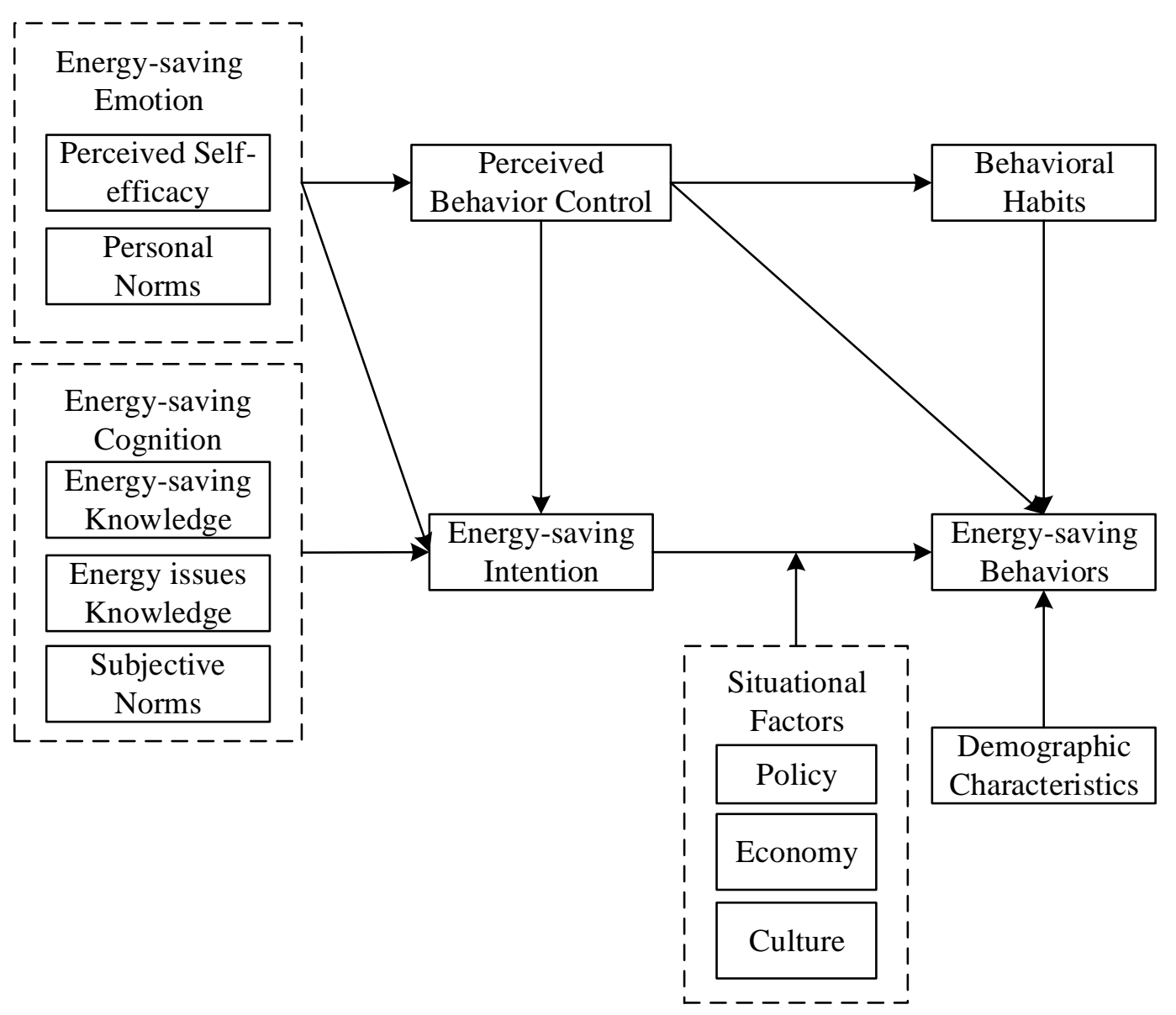

Fig. 1 Comprehensive model of energy-saving awareness and behaviors

\section{Summary}

This paper constructs the research model of energy-saving awareness and behaviors through the study of the influencing process of the energy-saving awareness and energy-saving behaviors of urban residents. The research model is based on the theory of planned behaviors, but it does not simply apply the theory, but deeply explores the influence mode of energy-saving awareness on energy-saving behaviors through the exploring the development of energy-saving awareness, therefore develops and inherits the theory of planned behaviors. Through the analysis of the formation process, the influencing factors of energy-saving behaviors are energy-saving knowledge, subjective norms, self-efficacy, personal norms, perceived behavior control and behavior habits; external factors such as policy factors, economic factors and cultural background can also exert influences on energy-saving behaviors; at the same time, the demographic characteristics of urban residents' gender, age, income level, educational level and family structure are also the influencing factors of energy-saving behaviors.

The establishment of this model is based on the study of document literature, combined with interdisciplinary related academic research, so the model has reasonability and applicability. In the process of establishing this model, the concept of influencing factors in the related research is combed, and the obstacles in conceptual understanding is removed for other scholars to conduct related research. However, the proposed model has not been tested in empirical demonstration. Therefore, in the future research, this theoretical model will be applied to the concrete research on energy-saving behaviors of urban residents, and the questionnaire is designed according to the theoretical model. By the empirical investigation and analysis, this paper also puts forward policy recommendations for policy making of guiding energy-saving behaviors of the residents. 


\section{References}

[1] I. Ajzen, B.L. Driver: Leisure Sciences, Vol. 13 (1991) No.3, p.185.

[2] J. Paul, A. Modi and J. Patel: Journal of Retailing \& Consumer Services, Vol. 29 (2016), p.123.

[3] M.F. Chen, P.J. Tung: International Journal of Hospitality Management, Vol. 36 (2014) No.1, p.221.

[4] J.C. Price, I.A. Walker and F. Boschetti: Journal of Environmental Psychology, Vol. 37 (2014) No.3, p.8.

[5] C.A. Klöckner: Global Environmental Change, Vol. 23 (2013) No.5, p.1028.

[6] Y.Q. Huo: The Scientific Reconstruct and Developmental Landscape of Consciousness World: A Study of the Advancement in Contemporary Psychology (Ph.D., Nanjing Normal University, China 2005), p.102. (In Chinese)

[7] X.X Chen: Psychological Exploration, Vol. 7 (1986) No.3, p.13. (In Chinese)

[8] P.C. Stern: Journal of Social Issues, Vol. 56 (2000) No.3, p.407.

[9] F.H. Kanfer, L. Gaelickbuys: Helping People Change: A Textbook of Methods, 4th ed. (Pergamon Press, US 1991), p.305.

[10]M. Fishbein, I. Ajzen: Psychological Bulletin, Vol. 84 (1977) No.5, p.888.

[11]A. Bandura: Educational Psychologist, Vol. 28 (1993) No.2, p.117.

[12]I. Ajzen: Organizational Behavior and Human Decision Processes, Vol. 50 (1991) No.2, p.179.

[13]L.Y. Mi: Research on Urban Residents Low Carbonization Energy Consumption Behavior and Policy Guidance (Ph.D., China University of Mining and Technology, China 2011), p.45. (In Chinese)

[14]T. Yue: Research on Influencing Factors and Guiding Policy of Energy-conservation Behavior of Urban Residents (Ph.D., China University of Mining and Technology, China 2014), p.58. (In Chinese) 